\title{
Analysis of Average Glandular Dose (AGD) and Associated Parameters for Conventional and Digital X-Ray Mammography
}

Ibrahim Idris Suliman ( $\square$ isuliman@squ.edu.om )

Sudan Atomic Energy Commission https://orcid.org/0000-0001-9646-8801

\section{Sawsan Mohamed}

Sudan Atomic Energy Commission

\section{Alaa Mahadi}

Sudan Atomic Energy Commission

\section{Einas Bashier}

Sudan Atomic Energy Commission

\section{A Farah}

Sudan Atomic Energy Commission

\section{Nada Hassan}

Sudan Atomic Energy Commission

\section{Nada Ahmed}

Sudan Atomic Energy Commission

\section{Mohamed Eisa}

Imam Muhammad bin Saud Islamic University: Imam Muhammad Ibn Saud Islamic University

\section{Ahmed El-Khayatt}

Imam Muhammad bin Saud Islamic University: Imam Muhammad Ibn Saud Islamic University

\section{Salem Sassi}

Prince Sultan Military Medical City

\section{Research Article}

Keywords: X-ray mammography, Radiation dose, Incident air kerma, Diagnostic reference levels (DRLs) , Compressed breast thickness (CBT), Radiation protection

Posted Date: August 18th, 2021

DOl: https://doi.org/10.21203/rs.3.rs-799884/v1

License: (c) (1) This work is licensed under a Creative Commons Attribution 4.0 International License. Read Full License 


\section{Abstract}

In this study, we determined the average glandular dose (AGD) from the craniocaudal (CC) and mediolateral oblique (MLO) views of 496 breasts ( 247 women) at eight clinics in Sudan. The incident air kerma from the X-ray tube output values and typical patient-specific breast exposure factors were measured. AGD values were inferred from the measured incident air kerma and breast-specific dose conversion coefficients. The AGD per CC and MLO projection and per woman ranged from 0.34-5.3 mGy (average: 2.46 ), 0.29-3.39 mGy (average: 1.50), and 0.6-7.4 mGy (average: 3.95). The proposed national diagnostic reference levels (mGy) are 3.48, 2.03, and 6.44 mGy for CC, MLO, and per woman, respectively. Establishing the proposed diagnostic reference levels is an essential step in ensuring patient protection from radiation and will help promote dose optimization for X-ray mammography at the national levels and beyond. The results provide important baseline data that can be used to formulate the national diagnostic reference levels.

\section{Introduction}

Breast cancer is the fifth most significant cause of cancer-related deaths worldwide, representing a significant health concern among women [1, 2]. Early diagnosis and treatment of breast cancer are crucial to reducing mortality $[3,4]$. Mammography screening can reduce breast cancer mortality by $15-$ $20 \%$ [5]. Thus, X-ray mammography is the first choice for the screening and diagnosis of breast cancer.

During X-ray mammography, the glandular tissue in the breast is subject to receiving a significant radiation-absorbed dose. The current breast-weighting and risk factors are approximately double the previously identified International Commission on Radiological Protection (ICRP) estimates established for radiation-induced breast cancer deaths, mainly due to the exposure of breast tissue to ionizing radiation $[6,7]$.

In diagnostic radiology, organizations such as ICRP emphasize setting and using diagnostic reference levels [6-10]. As defined by the ICRP, DRLs are a type of investigation level used as a tool to help determine the radiation dose optimizations [8]. The fact that significant variations in dose levels highlighted the need for DRL benchmarking in clinical practice. There was also a need to identify those hospitals that performed below average inpatient radiation exposure, thus necessitating optimization measures. The development of this concept has motivated several authors around the globe to propose DRLs in diagnostic and interventional radiology, including mammography [11-16]. Significant improvements in patient doses were reported as a result of establishing and implementing DRLs [17].

In 2017, the Sudan government passed an act [18] that established the Sudanese Nuclear \& Radiological Regulatory Authority (SNRRA) as an independent body that oversees all activities related to the peaceful applications of nuclear radiation. The SNRRA mandate comprises adopting guidelines, DRLs in medical imaging, and dose constraints for different exposure scenarios. Previously, several dose surveys were carried out in diagnostic radiology for optimization [19-22]. Despite these efforts, mammography was 
left behind, mainly because there are few mammography units across the country, which in itself is a source of concern. As of 2018, there were only 12 units across the country serving 35 million people in the population. With a lack of mammography-related radiation dose data available from Sudan and the region of Africa at large, it is not surprising that this is the first nationwide survey to be conducted in Sudan.

Herein, we aim to determine the average glandular dose (AGD) of radiation to promote dose optimization and acquire baseline data that will eventually help set national DRLs (NDRLs) for future dose optimization.

\section{Material And Methods}

We thought to estimate the AGD in 247 women who underwent mammographic X-ray examinations at eight clinics in Sudan. Women underwent symptomatic mammography but also screening mammography. The different types of investigated equipment included direct digital radiography (DR), computed radiography, and screen film (SF) radiography. Table 1 shows the studied mammography equipment information. For dose assessment, patient exposure parameters were retrospectively extracted from DICOM (Digital Imaging and Communications in Medicine) header. Individual patient consent was waived for this study.

Table 1

Mammography equipment information

\begin{tabular}{|lllllll|}
\hline Code & Make/model & $\begin{array}{l}\text { Country of } \\
\text { origin }\end{array}$ & Modality & $\begin{array}{l}\text { Target/filter } \\
\text { combination }\end{array}$ & $\begin{array}{l}\text { Year of } \\
\text { installation }\end{array}$ & $\begin{array}{l}\text { Institution } \\
\text { type }\end{array}$ \\
\hline M1 & Giotto & Italy & CR & Mo/Mo & 2010 & Government \\
\hline M2 & GE & USA & DR & Mo/Rh & 2012 & Government \\
\hline M3 & Philips & Netherlands & SF & Mo/Mo & 2007 & Private \\
\hline M4 & Lilyum/ & Italy & SF & Mo/Mo & 2010 & Private \\
& Metaltronica & & & & & \\
M5 & $\begin{array}{l}\text { MOMMAT } \\
\text { C/SIEMENS }\end{array}$ & Germany & CR & Rh/Al & 2012 & Private \\
\hline M6 & $\begin{array}{l}\text { Lilyum/ } \\
\text { Metaltronica }\end{array}$ & Italy & DR & Mo/Mo & 2014 & Private \\
\hline M7 & Philips & Netherlands & Dr & Mo/Mo & 2014 & Government \\
\hline M8 & OSH & & Dr & Mo/Mo & 2016 & Government \\
\hline
\end{tabular}

In mammography, the radiation dose is determined in terms of the AGD, the recommended dosimetric quantitative value of interest for radiation risk assessments in mammography (NCRP 1987, 1996) [23]. 
AGD is estimated from the measurements of the entrance surface air kerma (ESAK) and conversion coefficients that depend on beam quality (half-value layer) $[24,25]$. For each breast, the AGD is estimated for two views: the craniocaudal (CC; head to foot) and mediolateral oblique (MLO; from the middle of the chest out to the side of the body with the X-ray tube placed at an angle) views. In each of the CC and MLO views of the breast, the following parameters were recorded: compressed breast thickness (CBT), target and filtration material, tube peak kilovoltage $(\mathrm{kVp})$, and exposure current-time product (mAs). Other machine parameters, such as beam half-value layer $(\mathrm{HVL})$ and radiation output, were measured.

\section{Determination of the Average Glandular Dose (AGD)}

Average Glandular Dose (AGD) is the mean absorbed dose in the glandular tissue of the breast. Glandular tissue is the radiosensitive tissue of the breast, and therefore the AGD is recommended as a dose quantity of interest for radiation risk estimates in X-ray mammography (NCRP 1987, 1996) [23]. AGD is derived from measurements of the incident air kerma ( ) and applying conversion coefficients that depend on the radiation beam quality (HVL) determined by the anode /filter materials, breast thickness, and composition $[24,25]$. AGD is estimated from the in a three-step process:

First, the normalized X-ray tube output, , is obtained of the incident air kerma ( ) measured at a $60 \mathrm{~cm}$ focus-to-detector distance (d) with the breast compression plate in position using calibrated dose rate meter type Piranha (RTl; Ballad, Sweden). is defined as the air kerma measured at a point at the radiation field the center at patient's entrance or phantom, excluding the backscattered radiation. The normalized X-ray tube output, , is thereafter determined according to Eq. 1.

1

Where is the air kerma measured using a range of the tube voltage and exposure-time current product (mAs) value conditions encountered in mammography examinations for a particular mammography unit, a calibration curve of $\mathrm{Y}(\mathrm{d}, \mathrm{kV})$ versus $\mathrm{kV}$ values was obtained and fitted using a power function $[26,27]$.

Next, patient incident air kerma was determined from the $X$-ray tube output, $Y(d)$, corresponding to the specific $\mathrm{kV}$ value used during mammography corrected for the focal spot-to-surface distance, $\mathrm{d}_{\mathrm{FSD}}$, and mAs, according to Eq. 2:

2

AGD is then estimated from the measured values using conversion coefficients according to equations 3 
Where, is the coefficient to converts measured to AGD for a breast of $50 \%$ granularity; converts AGD for a breast of $50 \%$ granularity to that for breast granularity, $g$, of the same thickness. The $S$ correction factor represents the selected target/filter combination [26, 27].. Values of these conversion coefficients are tabulated as a function of the beam quality (HVL) for compressed breast thicknesses, composition but also for a reference phantom in the relevant International Atomic Energy Agency (IAEA) and the International Commission on Radiation Units and Measurements (ICRU) publications $[26,27]$.

\section{Result}

The results are presented for the AGD resulting from the CC and MLO views in one breast and the total dose per woman for 247 patients who underwent X-ray mammography at eight clinics in Sudan.

Table 2 shows the mammographic exposure settings and breast compression thickness used for the examinations. As shown, the exposure factors used $\mathrm{kV}$ and $\mathrm{mAs}$ across hospitals and ranged from 25.935.1 (average: 30.6 ) and 14.6-65.9 (average: 39.4 ), respectively. The mean compressed breast thickness (CBT) for the CC and MLO projections ranged from 29.0-42 $\mathrm{mm}$ (average: $37 \mathrm{~mm}$ ) and 30-50 mm (average: $39 \mathrm{~mm}$ ), respectively. All X-ray sets used the manual mode, with the beam quality selected by the technician. The selected tube voltage ranged from 23-36 kV. Figure 1. Shows the histogram of compressed breast thickness across the eight mammography devices; (a) CC view; (b) MLO view. As shown, BCT $40-45 \mathrm{~cm}$ have the highest frequency in both views. 
Table 2

Median and range of exposure settings and breast compression thickness

\begin{tabular}{|c|c|c|c|c|c|c|}
\hline \multirow[t]{2}{*}{ Code } & \multirow[t]{2}{*}{ Age (y) } & \multirow[t]{2}{*}{ kV } & \multirow[t]{2}{*}{ mAs } & \multicolumn{2}{|c|}{ BCT $(\mathrm{mm})$ per view } & \multirow{2}{*}{$\begin{array}{l}\text { The use of } \\
\text { AEC }\end{array}$} \\
\hline & & & & $\mathrm{CC}$ & MLO & \\
\hline M1 & 29 & 32 & 45 & 30 & 50 & Manual \\
\hline M2 & 27 & $29(26-31)$ & $55(37-99)$ & 48 & 54 & $\mathrm{AEC}$ \\
\hline M3 & 29 & $35(32-35)$ & $40(32-50)$ & 35 & 45 & Manual \\
\hline M4 & 22 & $32(28-35)$ & $30(25-40)$ & 35 & 30 & Manual \\
\hline M5 & 30 & $29(22-32)$ & $14(12-18)$ & 40 & 50 & Manual \\
\hline M6 & 30 & $26(24-27)$ & 25 & 30 & 33 & AEC \\
\hline M7 & 30 & $33(32-35)$ & 32 & 43 & 43 & AEC \\
\hline M8 & 50 & $29(27-33)$ & $58(35-120)$ & 40 & 42 & AEC \\
\hline Median & 29 & 31 & 36 & 38 & 44 & \\
\hline
\end{tabular}

The automatic exposure control (AEC) was used only for center $\mathrm{M} 2$, and the range of $\mathrm{mAs}$ varied widely between 34 and 316 at this center. At center M1, the operator maintained the mAs at a value of 45 , irrespective of breast thickness. At centers $M 3$ and $M 4$, the $\mathrm{mAs}$ were selected manually and ranged from 32-50 and 25-40 at each center, respectively. The highest mean mA value was 65 at mammography device M2. The lowest mean mA value was 31 at mammography device M4.

Table 3 presents the measured average kerma in the air and the calculated AGD for two views and 247 female patients at each mammography system (based on the measurement of 8 mammography devices). Figure 2 shows the boxplot distributions of the mean AGD at each hospital per CC and MLO projection. As illustrated, the AGD per CC and MLO projection and per woman ranged from 0.34-5.3 mGy (average: $2.46 \mathrm{mGy}$ ), 0.29-3.39 mGy (average: $1.50 \mathrm{mGy}$ ), and 0.6-7.4 mGy (average: $3.95 \mathrm{mGy}$ ), respectively. 
Table 3

Median values for the air kerma and the calculated average MGD for two views and for 247 female patients for each mammography system (based on the measurement of 8 mammography systems)

\begin{tabular}{|c|c|c|c|c|c|c|}
\hline \multirow[t]{2}{*}{ Unit } & \multirow[t]{2}{*}{$\mathbf{N}$} & \multirow{2}{*}{$\begin{array}{l}\mathrm{HVL} \\
(\mathrm{mm} \mathrm{Al} \text { eq })\end{array}$} & \multirow{2}{*}{$\begin{array}{l}\mathrm{Ki} \\
\text { (mGy) }\end{array}$} & \multicolumn{2}{|c|}{ MGD (mGy) per projection } & \multirow{2}{*}{$\begin{array}{l}\text { MGD (mGy) } \\
\text { Per woman }\end{array}$} \\
\hline & & & & $\mathrm{CC}$ & MLO & \\
\hline M1 & 50 & 0.38 & 0.20 & 2.90 & 1.7 & 4.60 \\
\hline M2 & 47 & 0.42 & 0.10 & 1.06 & 1.11 & 2.17 \\
\hline M3 & 43 & 0.42 & 0.23 & 2.42 & 1.97 & 4.39 \\
\hline M4 & 46 & 0.47 & 0.10 & 0.93 & 0.94 & 1.87 \\
\hline M5 & 44 & 0.21 & 1.25 & 0.33 & 0.30 & 0.63 \\
\hline M6 & 48 & 0.20 & 2.86 & 0.79 & 0.87 & 1.66 \\
\hline M7 & 50 & 0.39 & 0.18 & 1.10 & 1.10 & 2.20 \\
\hline M8 & 50 & 0.36 & 0.33 & 3.3 & 3.3 & 6.60 \\
\hline \multicolumn{2}{|c|}{ Median } & 0.39 & 0.22 & 1.08 & 1.11 & 2.19 \\
\hline \multicolumn{2}{|c|}{ First Quartile } & 0.32 & 0.16 & 0.90 & 0.92 & 1.82 \\
\hline \multicolumn{2}{|c|}{ Third Quartile } & 0.42 & 0.56 & 2.54 & 1.77 & 4.44 \\
\hline \multicolumn{2}{|c|}{ Interquartile ratio } & 1.3 & 3.5 & 2.8 & 1.9 & 2.4 \\
\hline
\end{tabular}

In the present study, two hospitals (25\%) presented doses that were higher than the established international DRLs. The ratio ( $\mathrm{max} / \mathrm{min}$ ) of AGD was as high as 16 for CC projections and 12 for MLO projections per woman.

\section{Discussion}

\section{Relationship between AGD and breast compressed thickness}

Automatic exposure control in imaging adjusts exposure factors according to patient characteristics, such as the breast compressed thickness in mammography. In this regard, devices were of three types: devices where AEC control both $\mathrm{kV}$ and $\mathrm{mAs}$ (M2 \& M8); devices that use the same mAs for all patients but $k V$ is slightly varied (M6 \& M7); devices with manual selection of both $k V$ and $m A s$ but use exposure charts (M3, M4 \& M5); and hospital which used fixed exposure factors (M1) resulting.

Figure 3 presents the estimated Mean Glandular dose as a function of compressed breast thickness (CBT). Several authors studied the correlation between MGD and CBT in X-ray mammography to 
investigate their influence in inpatient doses, showing a positive correlation between MGD and CBT [24, 25]. Figures $1 \mathrm{a} \& \mathrm{~b}$ follow this pattern showing a positive correlation between MGD and CBT because of the use of AEC to control both $\mathrm{kV}$ and mAs values. The correlation between MGD and CBT in other devices are greatly affected by using AEC or manual settings during a particular X-ray procedure.

\section{Dose optimization}

As suggested in the literature, optimization is needed when typical patients' doses exceed the corresponding established DRLs or doses associated with significant variations that cannot be explained either among hospitals or individual patients. In X-ray mammography, AGD depends on several factors: (1) parameters that affect the incident air kerma (e.g., exposure factors, beam quality, and focus-to-skin distance); and (2) mammography-related parameters (e.g., breast thickness and breast graduality). This study's correlation between MGD and CBT demonstrated the importance of using AEC in all mammography procedures. Furthermore, the AGD ratio (the maximum to minimum) among the studied eight centers were 16 and 12 in the CC and MLO views, respectively. Dose variations are clear evidence that radiation dose optimization is possible without risking the quality of diagnostic information.

As seen in Tables 2 and 3, high MGD is associated with high exposure and average breast thickness. Almost 7 out of the eight mammography devices used $28 \mathrm{kV}$ or higher for their examinations. The use of high $\mathrm{kV}$ increases the beam penetrability and increases the spatial resolution required in mammography. Hospital M6 used the lowest tube voltage ( $25 \mathrm{kV})$, corresponding to the lowest average breast thickness $(29 \mathrm{~mm})$, contrasting the dose used at hospital M2, which corresponds to $52 \mathrm{~mm}$. In general, mammography devices operate in an auto-filter mode, where the compressed breast thickness determines the $\mathrm{kV}$ and filter selection. The required tube current-exposure time was determined either via pre-exposure settings or by automatic exposure control, depending on device breast thickness. High MGD per woman is associated with high mAs values (M1 \& M8) devices.

In contrast, the lowest doses have shown at devices M5, M6 \& M7 correspond to the deployed lowest $m A s$. High MGD is generally associated with high mAs values irrespective of whether the device detector is an SF, CR, or DR device. The median dose for craniocaudal view images was lower than that for the mediolateral oblique view because the thickness for CC images was lower than that for MLO images. Generally, MGD is higher in MLO view are attributed to greater inclusion of pectoral muscle in MLO view, which is denser and has higher attenuation and hence higher radiation dose.

\section{Comparison with the literature}

Table 4 presents a comparison of AGD values obtained in this study with the results in the literature [2835]. The CC, MLO, and per-woman AGD values obtained in this study: $2.46 \mathrm{mGy}, 1.5 \mathrm{mGy}$, and $3.95 \mathrm{mGy}$, respectively. These values can be compared to the results of a study by Moran et al., who reported the AGD for CC and MLO projections, and per woman, of $1.8 \mathrm{mGy}, 1.95 \mathrm{mGy}$, and $3.7 \mathrm{mGy}$, respectively in Spain. In another study in Malaysia, the AGD was $1.54 \mathrm{mGy}, 1.82 \mathrm{mGy}$, and $3.37 \mathrm{mGy}$, respectively. In contrast, Thiele et al. in Australia reported AGD values of $1.6 \mathrm{mGy}$ and $4.6 \mathrm{mGy}$ in per view and per 
woman, respectively whereas Alizadeh in Iran the reported AGD values of $2.0 \mathrm{mGy}, 2.4 \mathrm{mGy}$, and $4.4 \mathrm{mGy}$ in CC, MLO, and per woman, respectively.

Table 4

Comparison of MGD values obtained in this study with the results presented in similar studies in the literature.

\begin{tabular}{|c|c|c|c|c|c|}
\hline \multirow[t]{2}{*}{ Data origin } & \multirow[t]{2}{*}{ Sample } & \multirow{2}{*}{$\begin{array}{l}\text { Mean BCT } \\
\text { (cm) }\end{array}$} & \multicolumn{2}{|l|}{ AGD (mGy) } & \multirow[t]{2}{*}{ Ref. } \\
\hline & & & Per view & Per woman & \\
\hline \multirow[t]{2}{*}{ Spain } & 5,034 & 52; CC: 49.0 & Mean CC:1.8 & Mean 3.75 & [28] \\
\hline & & MLO:54 & Mean MLO:1.95 & & \\
\hline Australia & & 42.0 & Mean:1.6 & Mean: 4.6 & [29] \\
\hline \multirow[t]{2}{*}{ Greece } & 250 & 42 & Mean:1.4; Mean CC:1.2 & Mean 2.7 & [30] \\
\hline & & & Mean MLO:1.5 & & \\
\hline \multirow[t]{3}{*}{ Malta } & 759 & 57.51 & Mean:1.07 & Mean 2.13 & [31] \\
\hline & & CC:53.8 & Mean CC:1.06 & & \\
\hline & & ML063.4 & Mean MLO:1.07 & & \\
\hline \multirow[t]{2}{*}{ Serbia } & 53 & CC:49.5 & Mean CC:2.8 & Mean 7.1 & [32] \\
\hline & & MLO:56 & Mean ML0:4.3 & & \\
\hline \multirow[t]{2}{*}{ Iran } & 298 & CC:49.7 & Mean CC:2.0 & Mean 4.4 & [33] \\
\hline & & MLO:58.5 & Mean MLO:2.4 & & \\
\hline \multirow[t]{3}{*}{ Ireland } & 2,910 & 61.4 & Mean CC:1.27 & Mean 2.61 & [34] \\
\hline & & CC: 60.5 & Mean MLO:1.34 & & \\
\hline & & MLO:63 & & & \\
\hline \multirow[t]{4}{*}{ Malaysia } & 300 & 41.0; CC:37.51 & Median CC:1.44 & Median & [35] \\
\hline & & MLO:44.5 & Median MLO: 1.65 & CC:3.37 & \\
\hline & & & & Median & \\
\hline & & & & MLO:3.21 & \\
\hline \multirow[t]{2}{*}{ 1.1 Sudan } & 247 & $C C=37.36$ & Median: CC = 1.08 & Median & This study \\
\hline & & $\mathrm{MLO}=39.18$ & $\mathrm{MLO}=1.11$ & 2.19 & \\
\hline
\end{tabular}

Our AGD values are almost half the doses reported by Ciraj-Bjelac et al. in Serbia, who reported AGD values of $2.8 \mathrm{mGy}, 4.3 \mathrm{mGy}$, and $7.1 \mathrm{mGy}$ in CC and MLO projections, and per woman, respectively. This study reported an average breast thickness of $49.5 \mathrm{~mm}$ and $56.0 \mathrm{~mm}$ for CC and MLO projections, 
respectively, compared to the average breast thickness of $37.6 \mathrm{~mm}$ and $39.2 \mathrm{~mm}$. Several studies have shown that assuming comparable exposure factors, MGD increases with breast thickness. Among the different studies presented in Table 4, only the study by Borg et al. in Malta showed a high average breast thickness of $53.8 \mathrm{~mm}$ and $63.4 \mathrm{~mm}$, but a low AGD of 2.13. Among the centers included in this study, the AGD per CC projection was higher than that presented for the MLO projection at six (75\%) of the hospitals studied. Even there is consensus that AGD increases with CBT, breasts with a similar average thickness may show differences in granularity, which is a significant determinant of radiation-induced risk. Pectoral muscle was denser than the rest of the breast muscles, which may be a reasonable explanation underlying this phenomenon [36]. The doses documented in this report are higher than the results of a study conducted by Baldelli in Ireland, who reported AGD values of $1.72 \mathrm{mGy}, 1.34 \mathrm{mGy}$, and $2.61 \mathrm{mGy}$ in $\mathrm{CC}$ and MLO projections, and per woman, respectively. The present study results are also higher than those reported in Malta and Greece (Table 4). From the obtained results, we propose that AGD values of $3.48 \mathrm{mGy}, 2.03 \mathrm{mGy}$, and $6.44 \mathrm{mGy}$ for CC and MLO projections, and per woman, respectively, be established as the NDRLs for Sudan. These represent the 75th percentile of the dose distributions of the mean hospital values. When compared with the other DRL values established in the literature, our values are comparable to those used in the United Kingdom (3.5 mGy) [37] and Belgium (2.46 mGy) [38].

Our study has its limitations. Due to the significant variations in compressed breast thickness, the ICRP recommends a minimum sample size of 50 women per mammography device for dosimetric studies to minimize dose variations. This criterion was met in two hospitals, M7 \& M8, mainly because the authors manually collected the data. Further, some difficulties were faced when obtaining these data, particularly for SF mammography, where patient exposure data were not archived.

\section{Conclusions}

This study revealed significant differences in radiation dose levels among hospitals and within the same hospital for the same type of examination. This is important when establishing recommendations for dose optimization. The results presented here provide the first dosimetric information related to the AGD per CC and MLO projections in mammography, and per woman in the country. The average breast thickness reported in this study could be used as the standard breast thickness for Sudanese women. These results constitute important steps when protecting patients from radiation exposure and will help promote dose optimization in X-ray mammography nationally and beyond. The study provides an important baseline data for dose optimizations and setting National Diagnostic Reference Levels.

\section{Declarations}

\section{Conflict of interest}

The author has no conflict of interest to declare.

\section{Funding:}


The authors extend their appreciation to the Deanship of Scientific Research at Imam Mohammad Ibn Saud Islamic University for funding this work through Research Group No. RG-21-09-45.

\section{References}

1. Kunosic, S., 2012. An analysis of application of mean glandular dose and factors on which it depends to patients of various age groups. Mammography-Recent Advances, pp.7-17.

2. Torre, L.A., Siegel, R.L., Ward, E.M. and Jemal, A., 2016. Global cancer incidence and mortality rates and trends-an update. Cancer Epidemiology and Prevention Biomarkers, 25(1), pp.16-27.

3. Garcia, M., A. Jemal, E. M. Ward, M. M. Center, Y. Hao, R. L. Siegel, and M. J. Thun. "Global cancer facts \& figures 2007. 2007." Atlanta, GA: American Cancer Society (2009).

4. DeSantis, Carol, Rebecca Siegel, and Ahmedin Jemal. "Breast cancer facts and figures 2013-2014." American Cancer Society 2013 (2013): 1-38.

5. Kopans, Daniel, Sara Gavenonis, Elkan Halpern, and Richard Moore. "Calcifications in the breast and digital breast tomosynthesis, 2011." The breast journal 17, no. 6: 638-44.

6. ICRP 1991 The 1990 recommendations of the international Commission on radiological protection.

7. Valentin, Jack. The 2007 recommendations of the international commission on radiological protection. Vol. 37, no. 2-4. Oxford: Elsevier, 2007.

8. ICRP 2017 ICRP Publication 135: Diagnostic reference levels in medical imaging Annals of the ICRP $461-144$

9. National Council on Radiation Protection and Measurement Diagnostic. Reference levels and achievable doses in medical and dental imaging: recommendations for the United States. Bethesda, MD. NCRP Report \#172, 2012.

10. European Commission (EC). Diagnostic Reference Levels in Thirty-six European Countries Part 2/2. Radiation protection No. 180 (Luxembourg: Publications Office of the European Union, 2014).

11. Couto, L.S., Freitas-Junior, R., Correa, R.S., Peixoto, J.E., Almeida, C.D., Rodrigues, D.C.N., Glassman, L.M. and Soares, L.R., 2019. Mean glandular dose in digital mammography in women with breast implants. Journal of Radiological Protection, 39(2), p.498.

12. Barufaldi, B., Schiabel, H. and Maidment, A.D., 2019. Design and implementation of a radiation dose tracking and reporting system for mammography and digital breast tomosynthesis. Physica Medica, 58, pp.131-40.

13. Abdi, Ahmed Jibril, Andreas Fieselmann, Heiderose Pfaff, Thomas Mertelmeier, and Lisbet Brønsro Larsen. "Comparison of screening performance metrics and patient dose of two mammographic image acquisition modes in the Danish National Breast Cancer Screening Programme." European journal of radiology 105 (2018): 188-194.

14. O'Leary D and Rainford L 2011), vol. Series): European Congress of Radiology 2011)

15. Power G, Manley M, Baldelli P, Keavey E and Phelan N 2019 Breast thickness based DRLs in screening mammography Physica Medica 67203 
16. Sánchez R, Vañó E, Soto J M F, Ten J I, Escaned J, Delgado C, García B, Magariño F C, Fernández J F D and Luna R J M 2020 Updating national diagnostic reference levels for interventional cardiology and methodological aspects Physica Medica 70 169-75

17. Hart D, Hillier M and Shrimpton P 2010 on Doses to patients from radiographic and fluoroscopic Xray imaging procedures in the UK Chilton: Health Protection Agency Centre for Radiation, Chemical and Environmental Hazards

18. Gibreel, H.E.H., Ahmed, M.M., Sam, A.K. and Suliman, I.I., 2019. Evaluation of Sudan Nuclear and Radiological Regulatory control act (2017) in light of IAEA safety standards. Progress in Nuclear Energy, 115, pp.158-168.

19. Ahmed, N.A., Basheir, E.H., Farah, A.B., Mohammedzein, T.S. and Suliman, I.I., 2020. Proposed National Diagnostic Reference Levels for Standard Radiographic X-Ray Procedures in Sudan. Radiation Protection Dosimetry, 190(4), pp.419-426.

20. Suliman I and Abdelgadir A H 2018 Patient radiation doses in intraoral and panoramic X-ray examinations in Sudan Physica Medica 46 148-52

21. Bashier EH, Suliman II. Multi-slice CT examinations of adult patients at Sudanese hospitals: radiation exposure based on size-specific dose estimates (SSDE). La radiologia medica. 2018 Jun 1,123(6):424-31.

22. Bashier, E.H. and Suliman, I.I., 2019. Radiation dose determination in abdominal CT examinations of children at Sudanese hospitals using size-specific dose estimates. Radiation protection dosimetry, 183(4), pp.444-449.

23. National Council on Radiation Protection and Measurements. "Quality assurance for diagnostic imaging." NCRP report no. 99 (1988)

24. Dance D, Skinner C, Young K, Beckett J and Kotre C 2000 Additional factors for the estimation of mean glandular breast dose using the UK mammography dosimetry protocol Physics in medicine \& biology 453225

25. Dance D, Young K and Van Engen R 2009 Further factors for the estimation of mean glandular dose using the United Kingdom, European and IAEA breast dosimetry protocols Physics in Medicine \& Biology 544361

26. International Commission on Radiation Measurements and Units. Patient dosimetry for X-rays used in Medical Imaging. ICRU report No. 74, ICRU, Bethesda, MD (2006).

27. International Atomic Energy Agency. Dosimetry in diagnostic radiology: an international code of practice. IAEATRS. No457,IAEA(2007).

28. Moran P, Chevalier M, Ten J, Fernandez Soto J and Vano E 2005 A survey of patient dose and clinical factors in a full-field digital mammography system. Radiat. Prot. Dosimetry. 114 375-9

29. Thiele D L, Irvine M, Want D and Bernardo M 2011 Diagnostic reference levels for mammography in BreastScreen Queensland Australasian physical \& engineering sciences in medicine 34 415-8

30. Tsapaki V, Tsalafoutas I, Poga V, Louizi A, Kottou S and Koulentianos E 2008 Investigation of breast dose in five screening mammography centres in Greece Journal of Radiological Protection 28337 
31. Borg M, Badr I and Royle G 2013 Mammography equipment performance, image quality and mean glandular dose in Malta Radiation protection dosimetry 156 168-83

32. Ciraj-Bjelac O, Beciric S, Arandjic D, Kosutic D and Kovacevic M 2010 Mammography radiation dose: initial results from Serbia based on mean glandular dose assessment for phantoms and patients Radiation protection dosimetry $14075-80$

33. lizadeh Riabi H, Mehnati P and Mesbahi A 2010 Evaluation of mean glandular dose in a full-field digital mammography unit in Tabriz, Iran Radiation protection dosimetry 142 222-7

34. Baldelli P, McCullagh J, Phelan N and Flanagan F 2011 Comprehensive dose survey of breast screening in Ireland Radiation protection dosimetry 145 52-60

35. Jamal N, Ng K and McLean D 2003 A study of mean glandular dose during diagnostic mammography in Malaysia and some of the factors affecting it The British journal of radiology 76 238-45

36. EC 2013a European guidelines for quality assurance in breast cancer screening and diagnosis. European Commission)

37. Young K, Burch A and Oduko J 2005 Radiation doses received in the UK Breast Screening Programme in 2001 and 2002 The British journal of radiology 78 207-18

38. Smans K, Bosmans H, Xiao M, Carton A and Marchal G 2005 Towards a proposition of a diagnostic (dose) reference level for mammographic acquisitions in breast screening measurements in Belgium Radiation protection dosimetry $117321-6$

\section{Figures}



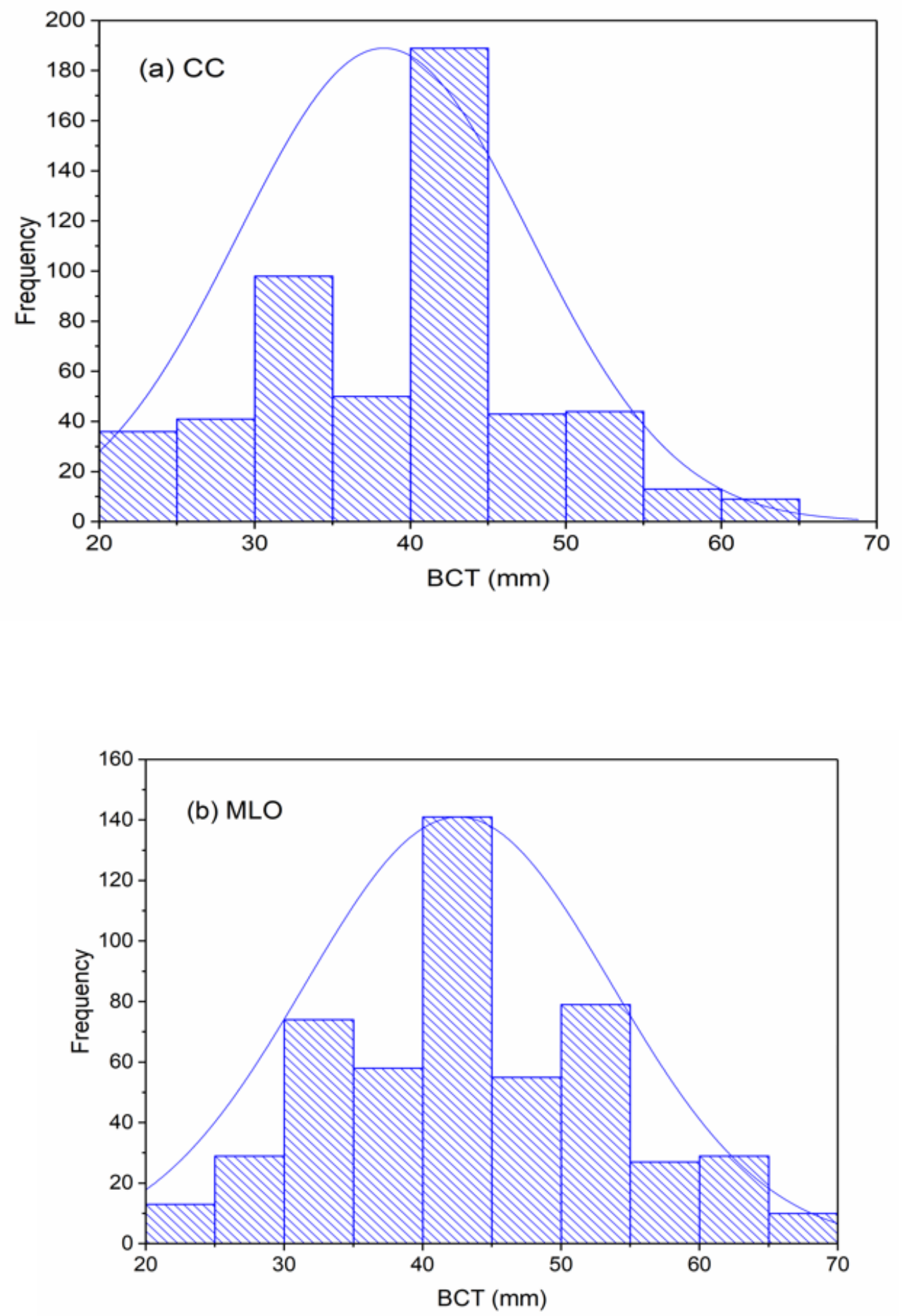

Figure 1

histogram of compressed breast thickness across the eight mammography devices, (a) CC view , (b) MLO view 

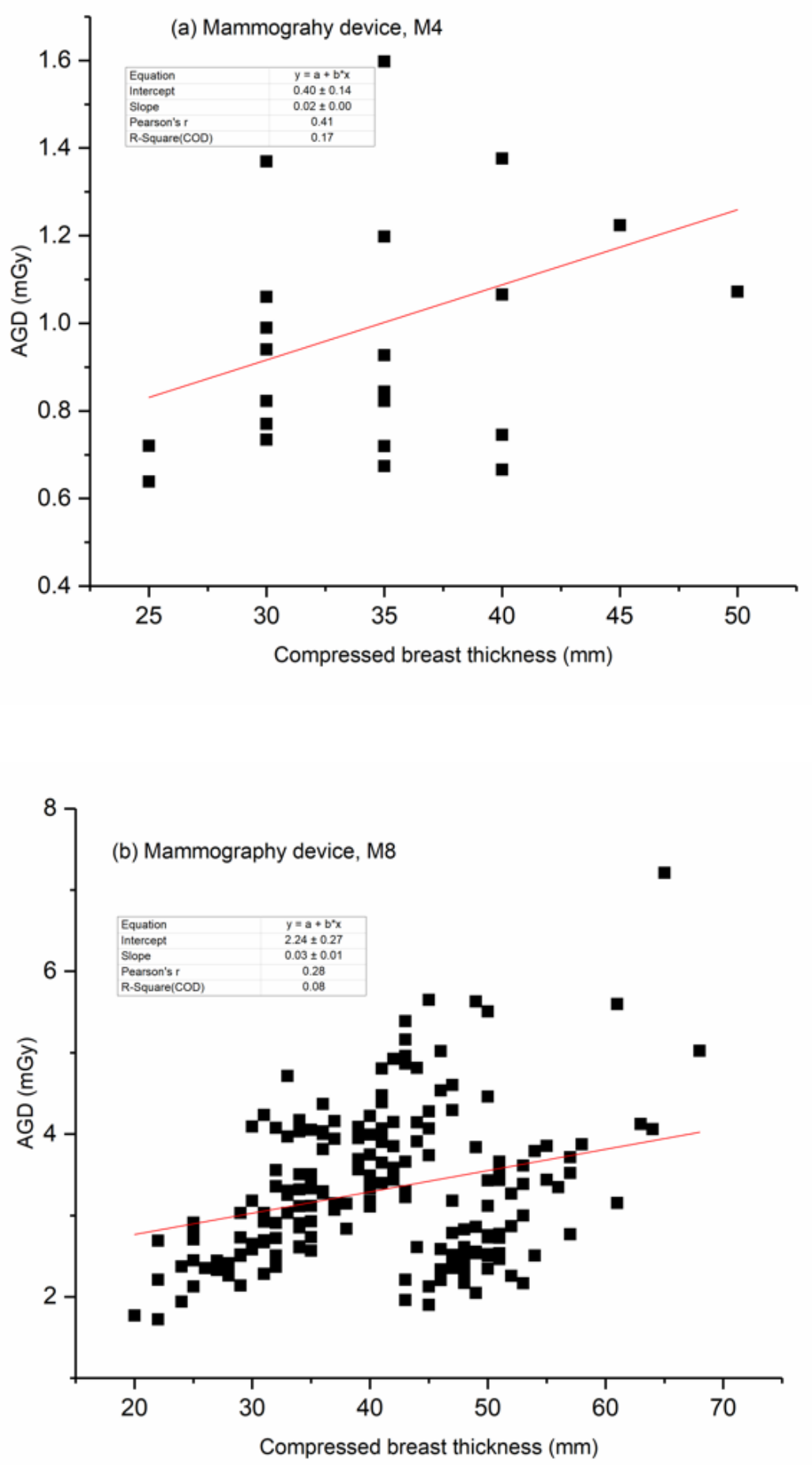

Figure 2

Mean Glandular dose as a function of compressed breast Thickness (CBT) (a) d) M4: Mo/Mo, SF, manual, (h) M8:, Mo/Mo, Dr, AEC 


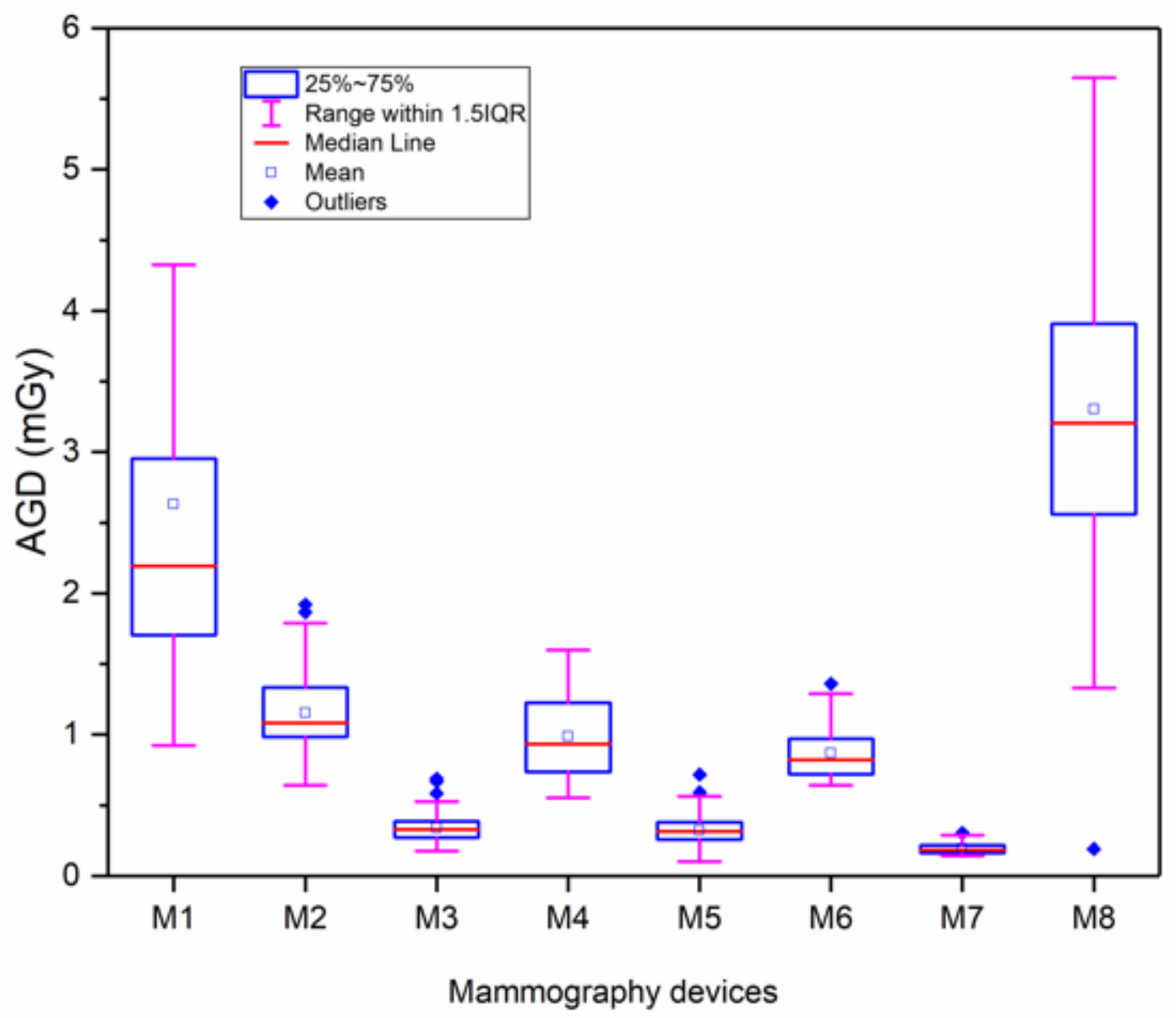

Figure 3

presents the estimated Mean Glandular dose as a function of compressed breast thickness (CBT). Several authors studied the correlation between MGD and CBT in X-ray mammography to investigate their influence in inpatient doses, showing a positive correlation between MGD and CBT [24,25]. 